\title{
A novel method for measurement of the occipital-cervical distance via the occiput- C4 distance
}

\author{
Chao Tang ${ }^{\dagger}$, Sheng Yang ${ }^{\dagger}$, Ye Hui Liao, Qiang Tang, Fei Ma, Qing Wang and De Jun Zhong ${ }^{*}$ (D)
}

\begin{abstract}
Background: The aim of the present study was to describe and measure the occipital-cervical distance by a novel method utilizing the occiput-C4 distance (OC4D) in normal subjects, as a proposed tool to guide restoration of vertical dislocations of the occipitocervical region in patients with basilar invaginations and for performing standardized testing of occipitocervical constructs.

Methods: We analyzed neutral, flexion, and extension lateral cervical spine radiographs of 150 asymptomatic subjects (73 males and 77 females) that were judged to be normal. The mean age of the included asymptomatic subjects was $48.0 \pm 8.4$ years old (range 20-69 years old; $48.4 \pm 10.2$ years old for males and $47.6 \pm 6.4$ years old for females). The OC4D was defined as the shortest distance from the center of the C4 vertebral body to the McGregor's line. Occipitocervical distances (OCDs) were measured and analyzed its correlation with OC4Ds. Two spine surgeons each performed three measurements of the OC4D and OCD from each asymptomatic subject, from which our reported average values were derived. The height, weight, and body mass index (BMI) of each subject were recorded and analyzed for their correlations with the OC4D and OCD.
\end{abstract}

Results: The OC4Ds from neutral, flexion, and extension lateral cervical spine radiographs were $69.0 \pm 6.9,68.9 \pm 6.8$, and $68.1 \pm 6.9 \mathrm{~mm}$, respectively. There was no significant difference in the OC4D values among neutral, flexion, and extension lateral cervical spine radiographs $(P>0.05)$. The neutral, flexion, and extension OCDs were $23.0 \pm 4.8$, $27.6 \pm 6.0$, and $13.8 \pm 4.7 \mathrm{~mm}$, respectively. In particular, the neutral OCD was significantly different from those in flexion and extension lateral cervical spine radiographs $(P<0.001)$. There was no significant correlation between OC4D and OCD in neutral, flexion, and extension ( $P>0.05$ for all). There were positive correlations between OC4D and height, as well as OC4D and weight, in neutral, flexion, and extension lateral cervical spine radiographs $(P<0.001$ for all). Furthermore, the intra-class correlation coefficients for inter- and intra-observer reliabilities of OC4Ds in neutral, flexion, and extension lateral cervical spine radiographs were significantly higher than those for OCDs $(P<0.001)$.

\footnotetext{
*Correspondence: zdj_1974@163.com

${ }^{\dagger}$ Chao Tang and Sheng Yang equally contributed to this paper as co-first authors.

Department of Spine Surgery, Affiliated Hospital of Southwest Medical University, No. 25 Taiping Street, Luzhou City 646000, China
}

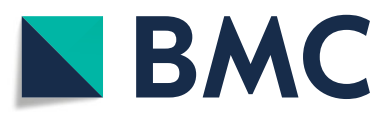

(c) The Author(s). 2020 Open Access This article is licensed under a Creative Commons Attribution 4.0 International License, which permits use, sharing, adaptation, distribution and reproduction in any medium or format, as long as you give appropriate credit to the original author(s) and the source, provide a link to the Creative Commons licence, and indicate if changes were made. The images or other third party material in this article are included in the article's Creative Commons licence, unless indicated otherwise in a credit line to the material. If material is not included in the article's Creative Commons licence and your intended use is not permitted by statutory regulation or exceeds the permitted use, you will need to obtain permission directly from the copyright holder. To view a copy of this licence, visit http://creativecommons.org/licenses/by/4.0/. The Creative Commons Public Domain Dedication waiver (http://creativecommons.org/publicdomain/zero/1.0/) applies to the data made available in this article, unless otherwise stated in a credit line to the data. 


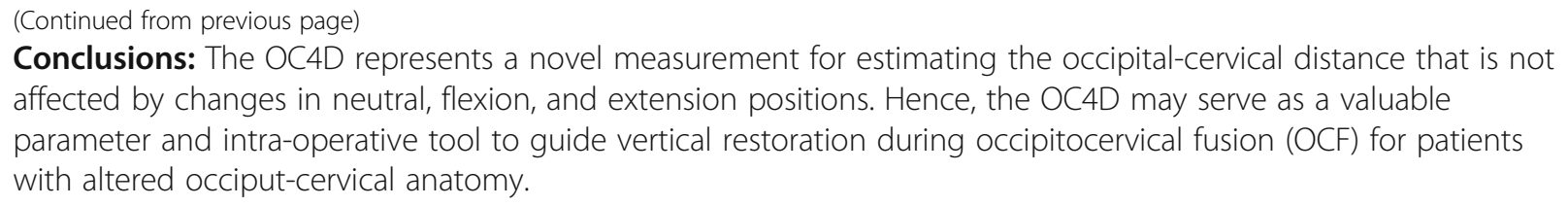

\section{Background}

Craniocervical joint instability caused by a congenital anomaly (e.g., basilar invagination), trauma, inflammatory disease, or a tumor may be an indication for occipitocervical fusion (OCF) [1]. During occipitocervical fixation and fusion, it is important to confirm that the occiput remains in a neutral balanced position in relation to the cervical spine. Previous studies have tended to focus on the effect of occipitocervical angle fixation on postoperative dyspnea/dysphagia and lower cervical spine degeneration [2, 3]. However, few studies have focused on the relationship between the distance of occipital-cervical vertical reduction and lower cranial nerve palsy following vertical over-distraction. Therefore, in the context of our present study, we considered that a normal occipital-cervical distance is likely important for avoiding over-distraction injuries to the cranial nerves and spinal cord during OCF. Previously, the occipitalcervical distance has been obtained by measuring the shortest distance from the most superior aspect of the C2 spinous process to the occipital protuberance [4]; however, this measurement method is significantly affected by even minimal head rotation. The $\mathrm{C} 4$ vertebral body, with a landmark at the mid-cervical level, is less affected by upper cervical spine motion/rotation, which makes it a more effective and versatile landmark for defining the occipitocervical neutral position during fusion surgery [5].

In the present study, we introduced and evaluated the occiput-C4 distance (OC4D) measurement method using lateral cervical spine radiographs from asymptomatic subjects. Additionally, we measured and compared the OC4Ds in different cervical positions and obtained normal value ranges, and further analyzed the correlation of OC4Ds with weight, height, and body mass index (BMI) in order to more comprehensively and accurately define the occipitocervical neutral position. Our findings may support the future use of our practical OC4D measurement method and its reference values for defining occiput-cervical vertical reduction during OCF.

\section{Methods}

\section{Subjects}

In this study, we included 150 sagittal-balanced cervical spine lateral radiographs, which were interpreted to be normal by two spine surgeons (i.e., absence of fractures or dislocations, absence of deformities, absence of severe osteophyte formation, absence of destruction of the vertebrae, and absence of spondylosis), from a radiographic database at the Affiliated Hospital of Southwest Medical University (China). Sagittal-balanced asymptomatic subjects were evaluated via both whole spine radiographs and cervical radiographs.

\section{Study sample}

The study population consisted of 73 males and 77 females with an average age of $48.0 \pm 8.4$ years (range 20-69 years; $48.4 \pm 10.2$ years for males and $47.6 \pm 6.4$ years for females). All subjects in the present study were from Southwest China, with an average height of $162.4 \pm 8.2 \mathrm{~cm}$ (males: $168.9 \pm 10.4 \mathrm{~cm}$, range: $156-182$ $\mathrm{cm}$; females: $159.7 \pm 6.8 \mathrm{~cm}$, range: $148-175 \mathrm{~cm}$ ) and average weight of $62.4 \pm 10.3 \mathrm{~kg}$ (males: $64.3 \pm 12.9 \mathrm{~kg}$, range: $49-92 \mathrm{~kg}$; females: $58.4 \pm 9.6 \mathrm{~kg}$, range: $42-85 \mathrm{~kg}$ ). Of the 150 participants included in the study, 79.3\% $(119 / 150)$ were of Han ethnicity. The proportions of the Yi, Zhuang, Manchu, Hui, Miao, and Mongolian ethnicities were $6.0 \%$ (9/150), $4.7 \%$ (7/150), $4.7 \%$ (7/150), $2.0 \%$ (3/150), $2.0 \%(3 / 150)$, and $1.3 \%(2 / 150)$, respectively. Approval for this study was obtained from the Ethics Committee of the Affiliated Hospital of Southwest Medical University (China).

\section{Measurements and procedure of OC4D and OCD}

Standard lateral cervical radiographs were obtained from each subject. The X-ray tube was centered at $\mathrm{C} 4$, and the radiographs were taken from a distance of $2 \mathrm{~m}$ from the subject's left side. Analysis of lateral neutral, flexion, and extension radiographs was performed using our novel OC4D measurement method. The OC4D was defined as the shortest distance from the center of the $\mathrm{C} 4$ vertebral body to the McGregor's line (Fig. 1). In contrast, the occipitocervical distance (OCD) was defined as the shortest distance between the most superior aspect of the $\mathrm{C} 2$ spinous process and the occipital protuberance (Fig. 2) [4]. Two spine surgeons calculated and documented the OC4D and OCD in each of the tested cervical radiographical positions in a blinded manner. These parameters were measured by both observers on three occasions over an interval of at least 2 weeks. 

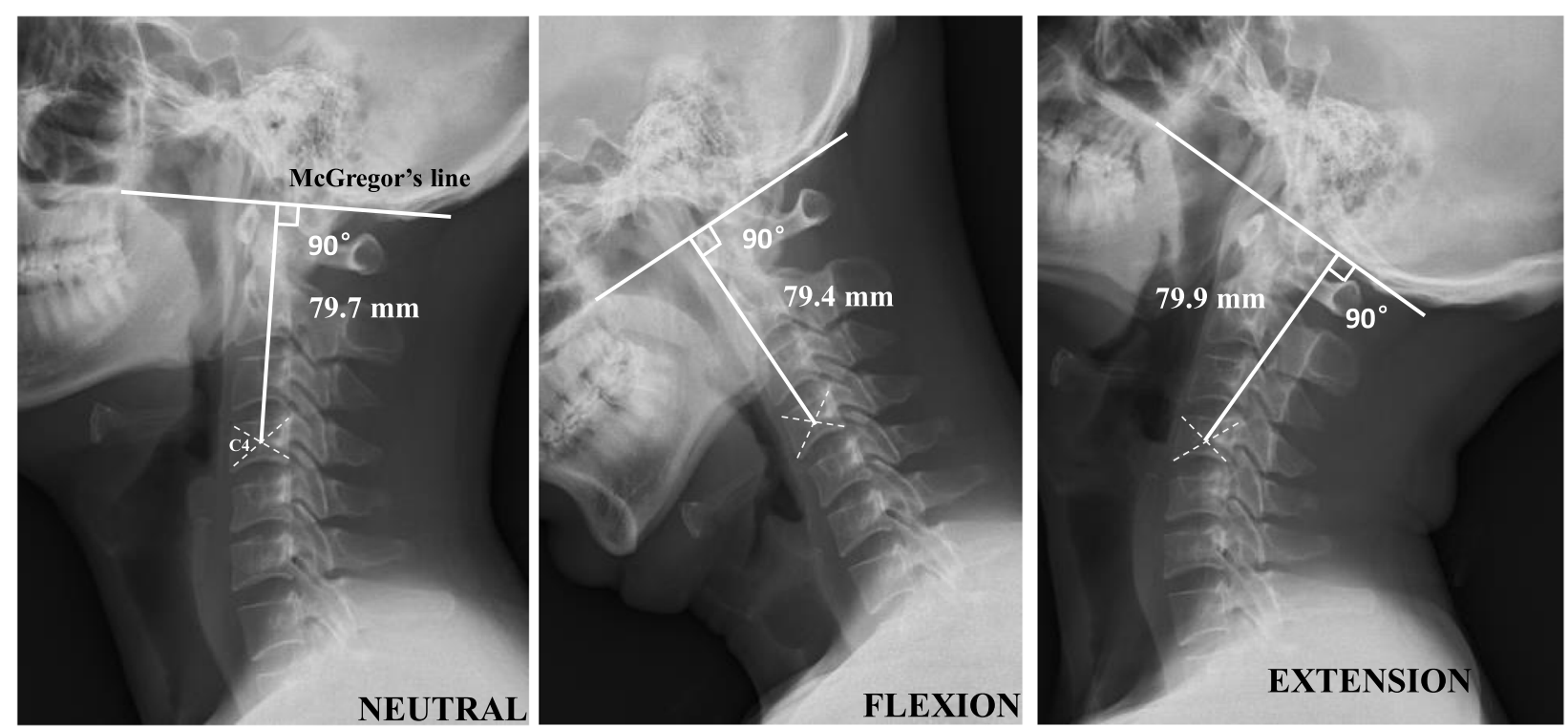

Fig. 1 A novel measurement method for estimating the occipital-cervical distance via the occiput-C4 distance (OC4D) in representative neutral, flexion, and extension positions. The OC4D was defined as the shortest distance from the center of the C4 vertebral body to the McGregor's line

To evaluate errors in these measurements, the differences among the means of the first, second, and third tracings for each of the variables were tested using paired t tests. No statistically significant differences were found. Therefore, the average measured values were used for subsequent comparisons. The height, weight, and BMI of each subject were recorded by the coauthors in this study, and BMI was calculated as follows:

$$
\mathrm{BMI}=\text { Weight }(\mathrm{kg}) / \text { Height }(\mathrm{m})^{2}
$$

\section{Statistical analysis}

SPSS software version 19.0 (SPSS Inc., Chicago, IL, USA) was used for all statistical analyses. Comparisons of the mean differences between groups that have been split on two independent variables (factor 1: radiographical position; factor 2: gender) were performed using Two-Way ANOVA and post-hoc tests. Pearson's coefficient was used to analyze correlation between OC4D and $\mathrm{OCD}$, and correlations of OC4D/OCD with height, weight, and BMI. Inter- and intra-observer reliabilities of OC4Ds and OCDs were assessed by calculating intraclass and inter-class correlation coefficients (ICCs). The calculated ICCs were interpreted according to the following standard convention: $0.90-1.0$, excellent agreement; 0.70-0.89, good agreement; 0.50-0.69, fair/ moderate agreement; $0.25-0.49$, low agreement; and $\leq$ 0.24 , poor or absent agreement [6]. Comparison of the ICC values was performed using the $\mathrm{Z}$ test. Data are
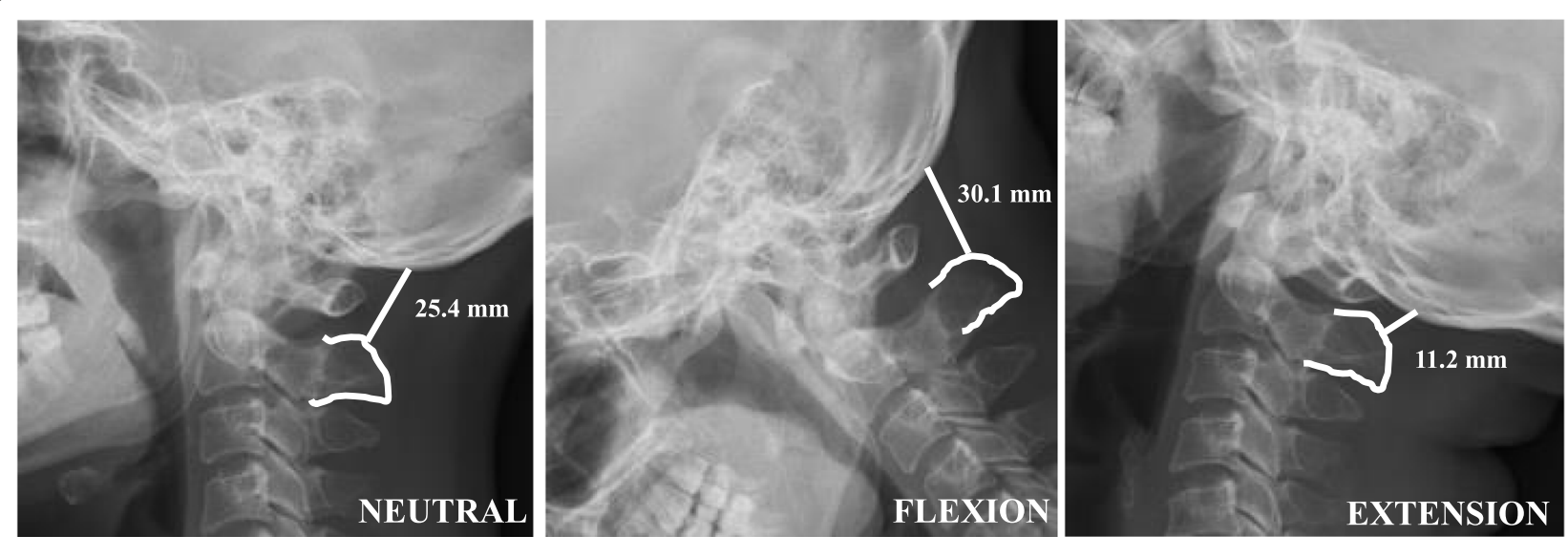

Fig. 2 Differences in the measured occipitocervical distance (OCD) due to cervical positions in neutral, flexion, and extension positions. OCD was defined as the shortest distance from the most superior aspect of the C2 spinous process to the occipital protuberance 
expressed as the mean \pm standard deviation of the mean, and differences between distributions were considered statistically significant at $P<0.05$. All reliability estimates are presented with a $95 \%$ confidence interval (CI).

\section{Results}

\section{Measurements of the OC4D and OCD}

The mean value of the OC4D in the neutral position was $69.0 \pm 6.9 \mathrm{~mm}$, which was not significantly different from the OC4D measured in flexion $(68.9 \pm 6.8 \mathrm{~mm})$ or extension $(68.1 \pm 6.9 \mathrm{~mm} ; P>0.05)$. In contrast, the mean neutral, flexion, and extension OCDs were $23.0 \pm$ $4.8 \mathrm{~mm}, 27.6 \pm 6.0 \mathrm{~mm}$ and $13.8 \pm 4.7 \mathrm{~mm}$, respectively; the neutral OCD was significantly greater than that in flexion, but was significantly smaller than that in extension $(P<0.001$; Table 1$)$.

For the OC4Ds, the values in males were significantly higher than those in females in neutral, flexion, and extension positions $(P<0.001$ for all). However, there was no significant gender differences for OCDs in neutral, flexion, or extension positions between males and females $(P>0.05$ for all; Table 2$)$.

\section{Correlations between $\mathrm{OC} 4 \mathrm{D}$ and $\mathrm{OCD}$}

Pearson's correlation coefficients showed that OC4D were weak negatively correlated with OCD $(r=-0.164$ in neutral, $r=-0.171$ in flexion, and $r=-0.038$ in extension), but there was no significant difference $(P>0.05$ for all) (Table 3).

Correlations of OC4Ds/OCDs with height, weight, and BMI Pearson's correlation coefficients showed that OC4Ds were significantly positively correlated with height $(r=$ 0.707 in neutral, $r=707$ in flexion, and $r=0.666$ in extension; $P<0.001$ for all), and there was also a moderate correlation between OC4D and weight $(r=0.541$ in neutral, $r=0.541$ in flexion, and $r=0.505$ in extension; $P<0.001$ for all). In contrast, there was no significant correlation between OC4D and BMI $(P>0.05$; Table 4).

For OCDs, there was a weak but significant correlation with height in each tested position $(r=0.284$ in neutral, $r=0.239$ in flexion, and $r=0.215$ in extension; $P<0.05$ for all). However, there was no significant correlation between OCD and weight, or between OCD and BMI, in neutral, flexion, and extension positions (Table 5).

Table 1 Measurements of the OC4D and OCD in neutral, flexion, and extension positions

\begin{tabular}{lllll}
\hline & $\begin{array}{l}\text { Neutral } \\
(n=150)\end{array}$ & $\begin{array}{l}\text { Flexion } \\
(n=150)\end{array}$ & $\begin{array}{l}\text { Extension } \\
(n=150)\end{array}$ & $\begin{array}{l}\text { Group difference } \\
(P \text { value })\end{array}$ \\
\hline OC4D $(\mathrm{mm})$ & $69.0 \pm 6.9$ & $68.9 \pm 6.8$ & $68.1 \pm 6.9$ & 0.302 \\
OCD $(\mathrm{mm})$ & $23.0 \pm 4.8$ & $27.6 \pm 6.0$ & $13.8 \pm 4.7$ & $F>N>E(P<0.05)$
\end{tabular}

Values represent the mean \pm standard deviation

$O C 4 D$ Occiput- $C 4$ distance, $O C D$ Occipitocervical distance
Table 2 Gender differences of the OC4D and OCD in neutral, flexion, and extension positions

\begin{tabular}{llll}
\hline & $\begin{array}{l}\text { Male } \\
(n=73)\end{array}$ & $\begin{array}{l}\text { Female } \\
(n=77)\end{array}$ & $\boldsymbol{P}$ value \\
\hline OC4D $(\mathrm{mm})$ & & & \\
Neutral & $73.0 \pm 6.4$ & $65.1 \pm 4.8$ & $<0.001$ \\
Flexion & $72.0 \pm 6.6$ & $64.4 \pm 4.9$ & $<0.001$ \\
Extension & $72.9 \pm 6.3$ & $65.1 \pm 4.9$ & $<0.001$ \\
OCD $(\mathrm{mm})$ & & & \\
Neutral & $22.4 \pm 5.0$ & $23.6 \pm 4.7$ & $>0.05$ \\
Flexion & $26.4 \pm 4.7$ & $28.8 \pm 7.0$ & $>0.05$ \\
Extension & $13.1 \pm 4.6$ & $14.5 \pm 4.7$ & $>0.05$ \\
\hline
\end{tabular}

Values represent the mean \pm standard deviation

$O C 4 D$ Occiput-C4 distance, $O C D$ Occipitocervical distance

\section{Inter- and intra-observer agreements}

The inter-observer reliabilities of OC4Ds were found to have ICCs of $0.945,0.953$, and 0.961 in neutral, flexion, and extension positions, respectively. Additionally, the ICC values in terms of intra-observer reliabilities for OC4Ds were $0.981,0.972$, and 0.968 in neutral, flexion, and extension positions, respectively (Table 6). Hence, all ICC values for both inter-and intra-observer reliabilities of OC4Ds in neutral, flexion, and extension positions were excellent, as they were all above 0.93. No significant difference was found between the measurements made by a single observer and those made by different observers. Finally, ICCs of inter- and intraobserver reliabilities for OC4D were significantly higher than those for OCD in each tested position $(P<0.05$; Table 6).

\section{Discussion}

In this study, we determined the reference values for estimating the occipital-cervical distance in neutral, flexion, and extension positions via our novel OC4D measurement method, which may provide a comprehensive and accurate estimation for vertical reduction of the occiput-cervical region during OCF. Importantly, the OC4D_as a simple, convenient, and highly reliable measurement of occiput-cervical distance-is not occluded by implants. More importantly, our present study revealed that the OC4D is not affected by changes in neutral, flexion, and extension cervical positions.

Conceptually, the occipitocervical neutral position is the functional and balanced position of the head atop the cervical spine. We considered that patients should

Table 3 Bivariate correlations between OC4D and OCD

\begin{tabular}{llll}
\hline & Neutral & Flexion & Extension \\
\hline Pearson correlation coefficient & -0.164 & -0.171 & -0.038 \\
$P$ value & 0.068 & 0.058 & 0.677 \\
\hline
\end{tabular}

OC4D Occiput-C4 distance, OCD Occipitocervical distance 
Table 4 Bivariate correlations of OC4Ds with height, weight, and $\mathrm{BMI}$

\begin{tabular}{|c|c|c|c|}
\hline & Height & Weight & $\mathrm{BMl}$ \\
\hline \multicolumn{4}{|l|}{ Neutral } \\
\hline Pearson correlation coefficient & 0.707 & 0.541 & 0.131 \\
\hline$P$ value & $<0.001$ & $<0.001$ & $<0.176$ \\
\hline \multicolumn{4}{|l|}{ Flexion } \\
\hline Pearson correlation coefficient & 0.707 & 0.541 & 0.126 \\
\hline$P$ value & $<0.001$ & $<0.001$ & 0.098 \\
\hline \multicolumn{4}{|l|}{ Extension } \\
\hline Pearson correlation coefficient & 0.666 & 0.505 & 0.111 \\
\hline$P$ value & $<0.001$ & $<0.001$ & 0.145 \\
\hline
\end{tabular}

have a normal occipitocervical angle and occiputcervical distance in this neutral position. Sherekar et al. [7] measured the occipito-C2 angle in 518 asymptomatic volunteers (261 male and 257 female subjects), and obtained values of $14.66 \pm 9.5^{\circ}$ in males and $15.59 \pm 8.26^{\circ}$ in females. Many researchers have reported that nonnormal occipitocervical angles lead to poor postoperative fusion, and even severe dysphagia and/or dyspnea during OCF [3, 8-10]. However, it remains unknown whether dysphagia and/or dyspnea are mostly due to mechanical airway obstruction caused by a non-normal occipitocervical angle. We believe that surgeons should pay more attention to the lower cranial nerve stretch airway obstruction caused by over-distraction of the occiputcervical vertical distance. Shigeto et al. reported that the mechanism of dysphagia is not simply associated with the $\mathrm{O}-\mathrm{C} 2$ angle, but that it also involves global craniocervical alignment in an individual patient, including the occiput-cervical distance [11]. Wang et al. reported that performing OCF in the over-distraction position to treat vertical atlantoaxial dislocation may caudally displace the brainstem relative to the cranial base, resulting in

Table 5 Bivariate correlations of OCDs with height, weight, and BMI

\begin{tabular}{llll}
\hline & Height & Weight & BMI \\
\hline $\begin{array}{llll}\text { Neutral } \\
\quad \text { Pearson correlation coefficient }\end{array}$ & 0.284 & 0.100 & -0.170 \\
$\quad \begin{array}{l}P \text { value } \\
\text { Flexion }\end{array}$ & $<0.001$ & 0.27 & 0.059 \\
$\quad \begin{array}{l}\text { Pearson correlation coefficient } \\
\quad 0 \text { value }\end{array}$ & 0.239 & 0.036 & -0.180 \\
$\begin{array}{l}\text { Extension } \\
\quad \text { Pearson correlation coefficient }\end{array}$ & 0.007 & 0.688 & 0.066 \\
$\quad P$ value & 0.017 & 0.055 & -0.133 \\
\hline OCD Occipitocervical distance, BMI Body mass index & & \\
\end{tabular}

traction injury to the 9th, 10th, and 11th lower cranial nerves [12].

In 1999, Phillips et al. first measured the occiputcervical distance of OCD by measuring the shortest distance from the most superior aspect of the $\mathrm{C} 2$ spinous process to the occipital protuberance in 30 asymptomatic subjects. In this initial study, the value of the OCD in the neutral position was $21.5 \pm 1.22 \mathrm{~mm}$, and it was significantly different from OCD values measured in flexion $(28.0 \pm 1.32 \mathrm{~mm})$ and extension $(14.8 \pm 1.48 \mathrm{~mm})$ [4]. Seong et al. measured OCDs in 200 normal, sagittal balanced patients (100 male and 100 female patients), and the mean neutral OCD was $22.98 \pm 5.10 \mathrm{~mm}$ (range, 9.88-38.64 mm), which was significantly different from those in flexion and extension positions [5]. In our present study, the mean neutral, flexion, and extension OCDs were $23.0 \pm 4.8 \mathrm{~mm}, 27.6 \pm 6.0 \mathrm{~mm}$ and $13.8 \pm 4.7$ $\mathrm{mm}$, respectively, and we also found that these OCDs were significantly different from one another in neutral, flexion, and extension positions. Unfortunately, correlations between OCD with height, weight, and BMI have not been reported in previous studies. In this study, there was a weak but significant correlation between OCD and height in neutral, flexion, and extension positions, but there was no significant correlation of OCD with weight and BMI. We measured the occiput-cervical distance via the OC4D, and the mean neutral OC4D was found to be $69.0 \pm 6.9 \mathrm{~mm}$. Importantly, this neutral OC4D value was not significantly different from those measured in flexion $(68.9 \pm 6.8 \mathrm{~mm})$ or extension $(68.1 \pm 6.9 \mathrm{~mm})$. Seong et al. found that the posterior border of $\mathrm{C} 4$ serves as a landmark in the apex of cervical lordosis, and that it is therefore the least affected by the cervical curve [5]. We hypothesized that the $\mathrm{C} 4$ vertebral body, being the central point of the cervical sequence, is the least affected by motion of the cervical position. Hence, the shortest distance from the center of the $\mathrm{C} 4$ vertebral body to the McGregor's line in each cervical position can be regarded as the radius of a circle positioned at the center of the $\mathrm{C} 4$ vertebral body and tangent to the McGregor's line (Fig. 3). Additionally, in our present study, we found significant positive correlations between OC4D and height, as well as between OC4D and weight, among which OC4D had a stronger correlation with height compared to that with weight. In contrast, the correlation between OC4D and BMI was weak and was not statistically significant. And we also found there was no significant correlation between OC4Ds and OCDs in this study. On the one hand, it is due to the difference of measurement methods. On the other hand, it is more important that variation of C2 spinous process has great influence on the individual difference of measurement results [13]. 
Table 6 Inter- and intra-observer reliabilities of OC4Ds and OCDs

\begin{tabular}{|c|c|c|c|c|c|c|c|}
\hline & & OC4D & & OCD & & & $P$ value* \\
\hline & ICC & Std error & $95 \% \mathrm{Cl}$ & ICC & Std error & $95 \% \mathrm{Cl}$ & \\
\hline Neutral & & & & & & & \\
\hline inter-observer reliability & 0.945 & 0.185 & $0.921-0.965$ & 0.785 & 0.254 & $0.689-0.814$ & $<0.05$ \\
\hline intra-observer reliability & 0.981 & 0.124 & $0.941-0.988$ & 0.832 & 0.239 & $0.812-0.841$ & $<0.05$ \\
\hline Extension & & & & & & & \\
\hline inter-observer reliability & 0.953 & 0.173 & $0.942-0.971$ & 0.654 & 0.312 & $0.638-0.664$ & $<0.001$ \\
\hline intra-observer reliability & 0.972 & 0.142 & $0.953-0.985$ & 0.671 & 0.301 & $0.651-0.685$ & $<0.001$ \\
\hline Flexion & & & & & & & \\
\hline inter-observer reliability & 0.961 & 0.156 & $0.948-0.987$ & 0.681 & 0.289 & $0.678-0.688$ & $<0.05$ \\
\hline intra-observer reliability & 0.968 & 0.151 & $0.955-0.989$ & 0.695 & 0.262 & $0.684-0.715$ & $<0.001$ \\
\hline
\end{tabular}

OC4D Occiput-C4 distance, OCD Occipitocervical distance

*Comparison of the ICC values between OC4D and OCD using the $Z$ test

We found that our novel OC4D measurement has unique advantages compared with those of the OCD in previously reported studies $[4,5,13]$. First, we found that the OC4D was a more accurate parameter compared to OCD in our present study. Additionally, in terms of the OCD, previous studies have demonstrated significant inter-individual morphologic variation in the $\mathrm{C} 2$ spinous process (including gender differences). Jiang et al. found that variations in the $\mathrm{C} 2$ spinous process may affect the OCD value, and that there was a significant difference in OCD values between male and female subjects [13]. Additionally, the inter- and intra-observer reliabilities of OCDs had ICC values of only 0.651 and
0.754 in a previous study [5]. In the present study, the ICC values of inter- and intra-observer reliabilities for OCDs were moderate to good based on evaluation using standard conventions (see Methods section). We found that the posterior margin of the hard palate, occipital bone, and $\mathrm{C} 4$ vertebra (with less bone variation) were clear on lateral radiographs. The ICC values of interand intra-observer reliabilities for OC4Ds were more than 0.93 in neutral, flexion, and extension positions, which were significantly higher than those for OCDs. Second, we found that the OC4D was less affected by different positions of the head and neck in neutral, flexion, or extension positions. The alignment of the

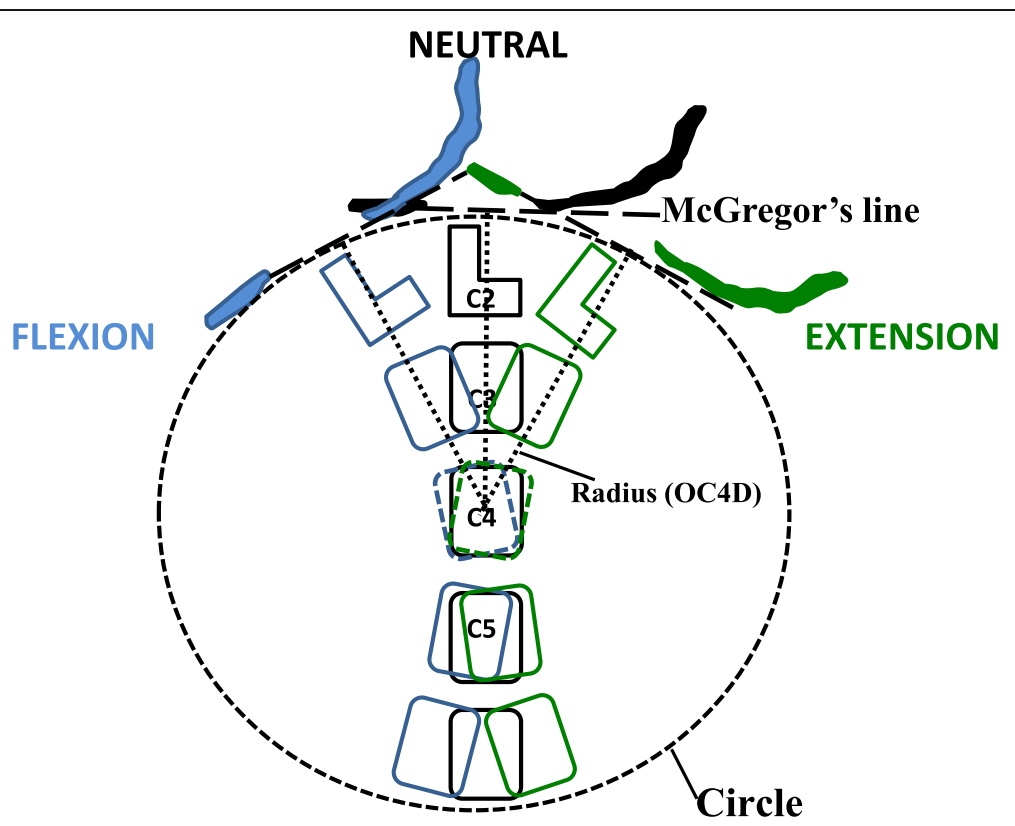

Fig. 3 The vertebral body of C4, an apex most visible on radiographs and least affected by the cervical curve, was designated as a landmark. The OC4D can be regarded as the radius of a circle positioned at the center of the C4 vertebral body and tangent to the McGregor's line 
subaxial spine can influence the occipitocervical alignment required to ensure a functional position of the occiput. However, this variable was not specifically measured in the current study. At present, only a few studies have reported OCD measurements and have shown that neutral OCDs are significantly different from those in flexion and extension positions $[4,5,10]$. In contrast, in our present study, there was no significant difference in the OC4Ds among neutral, flexion, and extension positions (whereas there was for OCDs). This finding may have clinical significance for the use of the OC4D in guiding reduction during operations when the occiput-cervical region is not in a neutral position. Third, the OC4D is not occluded by implants and may therefore represent a valuable intraoperative tool for designing of fusion implants and testing of restoration in the operating room. However, there are no reports showing that the $\mathrm{C} 2$ spinous process can be occluded by fixed implants during OCF and that the implants could affect OCD measurements (Fig. 4). Previous literature has stated that it may be difficult to visualize the tip of the dens on radiographs, or that the dens may be absent or fixed in an abnormal position in many conditions under which OCF is performed [14, 15]. Therefore, it may be difficult and inaccurate to evaluate vertical reduction of the occipitocervical region by the distance from the odontoid tip to the McGregor's line during surgery. Wang et al. first described lower cranial nerve palsy following vertical over-distraction after OCF in four patients who had atlantoaxial dislocation with or without basilar invagination, and the symptoms of all patients were alleviated to different extents by releasing the screw

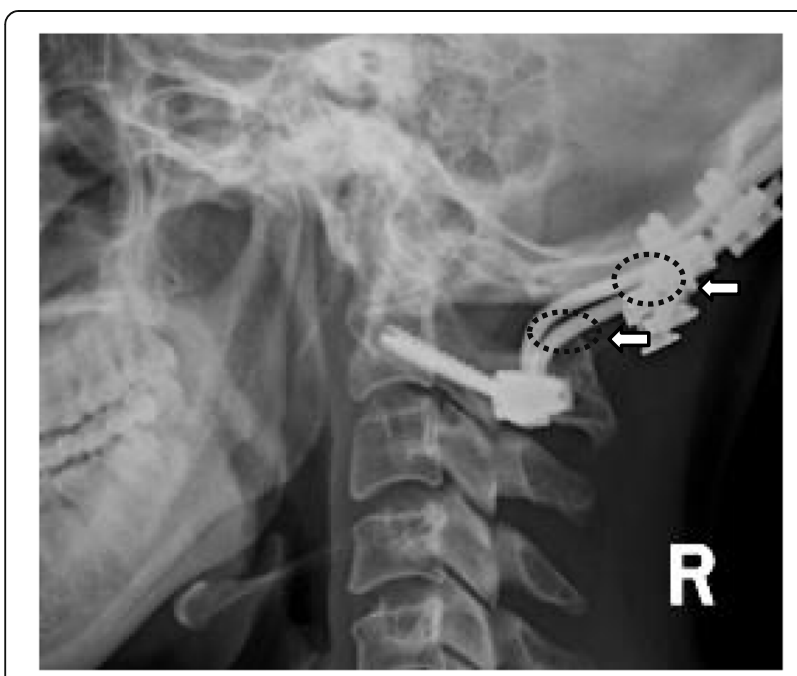

Fig. 4 The C2 spinous process and occipital protuberance can be occluded by fixed implants during occipital-cervical fusion (OCF) and the implants could affect the measurements of the occipitocervical distance $(O C D)$ cap and recovery to partial reduction of the occipitoatlantal anatomy [12]. However, our novel OC4D method avoids the occlusion caused by implants and the uncertainty of bony landmarks on radiographs, and therefore may represent a useful tool for estimating and testing the restoration of occipitoatlantal anatomy via regulation of fixed implants.

Limitations of the present study included the demographic data not being matched for age, as well as our sample size being relatively small. In spite of these limitations, our study presented a new method for measurement of the occipital-cervical distance, which may have practical valuable for guiding and testing the restoration condition of the occipital-cervical region. Another limitation of this study is that only cervical spinal radiographs were analyzed, as there were no data regarding the overall sagittal alignment of the spine. Although previous studies have reported that cervical curvature can be affected by overall spinal sagittal imbalance [16-19], only normal subjects with a normal cervical curvature were included in our present study, and we found no difference in OC4Ds as a function of changes in cervical curvature in neutral, flexion, and extension positions. However, we also recognize that cervical curvature changes can accelerate cervical degeneration, which may affect the results of OC4D measurements. Thus, future studies are needed to obtain more reliable measurements regarding cervical and overall spine sagittal alignment parameters, and to further explore the effect of spinal sagittal parameters on the OC4D. In addition, this present study did not provide the OC4D in patients with craniocervical joint instabilities as a clinically relevant comparator. Hence, we will measure the OC4D values of patients with craniocervical malformation as well as analyze the effect of OC4D fixation selection on the clinical efficacy and patient complications during OCF in future research.

\section{Conclusions}

In this study, we proposed and introduced a new OC4D method for estimating the occipital-cervical distance via the shortest distance from the center of the $\mathrm{C} 4$ vertebral body to the McGregor's line (i.e. the OC4D). We found that OC4Ds were not significantly different across neutral, flexion, or extension positions in males or females, and that OC4Ds were significantly positively correlated with both height and weight. Hence, our findings suggest that the OC4D may represent a valuable parameter and intraoperative tool for guiding vertical restoration during $\mathrm{OCF}$ for patients with altered occiput-cervical anatomy.

\section{Abbreviations}

OC4D: Occiput-C4 distance; OCD: Occipitocervical distance; BMI: Body mass index; ICCs: Intra-class and inter-class correlation coefficients;

OCF: Occipitocervical fusion 


\section{Acknowledgements}

We thank LetPub (www.letpub.com) for its linguistic assistance during the preparation of this manuscript.

The manuscript submitted does not contain information about medical device(s)/drug(s).

\section{Authors' contributions}

All authors made substantial contributions to this article. TC and ZDJ conceived the original study and developed the protocol together with YS. TC and ZDJ conceived and designed the study. TC, YS, LYH, TQ and MF participated in the study and gathered data. YS, LYH, and WQ analyzed and interpreted the data. TC initially drafted the manuscript, ZDJ and WQ statistically analyzed and ensured the accuracy of the data, and TC, ZDJ, and YS conducted the revision and editing of the manuscript. All authors have read and approved the final version of the manuscript and affirm that the work has not been submitted or published elsewhere, in whole or in part.

\section{Funding}

No funding was received in support of this work.

\section{Availability of data and materials}

Data will be available upon request to the first author, TC.

\section{Ethics approval and consent to participate}

The study protocol for the present study was approved by the Ethics Committee of the Affiliated Hospital of Southwest Medical University.

\section{Consent for publication}

All participants provided their written consent to publish their data and accompanying images.

\section{Competing interests}

The authors declare that they have no competing interests.

Received: 14 February 2020 Accepted: 3 June 2020

Published online: 15 June 2020

\section{References}

1. Grob D. Posterior occipitocervical fusion in rheumatoid arthritis and other instabilities. J Orthop Sci. 2000;5:82-7.

2. Masanori I, Masashi N, Mitsuru T, et al. The O-C2 angle established at occipito- cervical fusion dictates the patient's destiny in terms of postoperative dyspnea and/or dysphagia. Eur Spine J. 2014;23:328-36.

3. Inada T, Furuya T, Kamiya $K$, et al. Postoperative increase in occiput-C2 angle negatively impacts subaxial Lordosis after Occipito-upper cervical posterior fusion surgery. Asian Spine J. 2016;10:744-7. https://doi.org/10. 4184/asj.2016.10.4.744.

4. Phillips FM, Phillips CS, Wetzel FT. Occipitocervical neutral position. Possible surgical implications. Spine (Phila Pa 1976). 1999;24:775-8.

5. Seong $D$, Chang $H$, Jiwoon $L$, et al. Occipitocervical inclination: new radiographic parameter of neutral occipitocervical position. Eur Spine J. 2017;26:2297-302. https://doi.org/10.1007/s00586-017-5161-0.

6. Matsuyama $Y$, Hasegawa $Y$, Yoshihara $H$, et al. Hip-spine syndrome: total sagittal alignment of the spine and clinical symptoms in patients with bilateral congenital hip dislocation. Spine (Phila Pa 1976). 2004;29:2432-7.

7. Sherekar SK, Yadav YR, Basoor AS, et al. Clinical implications of alignment of upper and lower cervical spine. Neurol India. 2006;54:264-7.

8. Matsunaga S, Onishi T, Sakou T. Significance of occipitoaxial angle in subaxial lesion after occipitocervical fusion. Spine. 2001;26:161-5.

9. Logroscino CA, Genitiempo M. Relevance of the cranioaxial angle in the occipitocervical stabilization using an original construct: a retrospective study on 50 patients. Eur Spine J. 2009;18(Suppl 1):7-12. https://doi.org/10. 1007/s00586-009-0985-x

10. Veena S, Rebecca M, Pirjo M, et al. Airway adverse events following posterior occipito-cervical spinal fusion. J Clin Neurosci. 2017;39:124-9. https://doi.org/10.1016/j.jocn.2016.12.036.

11. Shigeto $E$, Kyousuke $H$, Tetsuro O, et al. Swallowing function after occipitocervical arthrodesis for cervical deformity in patients with rheumatoid arthritis. Neuro Rehabil. 2015:37:299-304. https://doi.org/10. 3233/NRE-151262.
12. Wang $\mathrm{Q}$, Wu X, Tan $\mathrm{M}$, et al. Is anatomic reduction better than partial reduction in patients with vertical Atlantoaxial dislocation? World Neurosurg. 2018;114:e301-5. https://doi.org/10.1016/j.wneu.2018.02.176.

13. Tan J, Liao G. Evaluation of occipitocervical neutral position using lateral radiographs. J Orthop Surg Res. 2014;9:87. https://doi.org/10.1186/s13018014-0087-2.

14. Harris JH, Carson GC, Wagner LK. Radiologic diagnosis of traumatic occipitovertebral dissociation: 2. Comparison of three methods of detecting occipitovertebral relationships on lateral radiographs of supine subjects. AJR Am J Roentgenol. 1994;162:887-92. https://doi.org/10.2214/ajr.162.4. 8141013.

15. Uno K, Kataoka O. Occipitoatlantal and occipitoaxial hypermobility in Down syndrome. Spine (Phila Pa 1976). 1996;21:1430-4.

16. Knott PT, Mardjetko SM. The use of the T1 sagittal angle in predicting overall sagittal balance of the spine. Spine J. 2010;10(11):994-8. https://doi. org/10.1016/j.spinee.2010.08.031.

17. Roussouly P, Pinheiro-Franco JL. Sagittal parameters of the spine: biomechanical approach. Eur Spine J. 2011;20(Suppl 5):578-85.

18. Lin BJ, Hong KT, Lin C, et al. Impact of global spine balance and cervical regional alignment on determination of postoperative cervical alignment after laminoplasty. Medicine (Baltimore). 2018;97(45):1-7. https://doi.org/10. 1097/MD.0000000000013111.

19. Le Huec JC, Thompson W, Mohsinaly Y, et al. Sagittal balance of the spine. Eur Spine J. 2019. https://doi.org/10.1007/s00586-019-06083-1.

\section{Publisher's Note}

Springer Nature remains neutral with regard to jurisdictional claims in published maps and institutional affiliations.
Ready to submit your research? Choose BMC and benefit from:

- fast, convenient online submission

- thorough peer review by experienced researchers in your field

- rapid publication on acceptance

- support for research data, including large and complex data types

- gold Open Access which fosters wider collaboration and increased citations

- maximum visibility for your research: over $100 \mathrm{M}$ website views per year

At $\mathrm{BMC}$, research is always in progress.

Learn more biomedcentral.com/submissions 